\title{
Applying Adult Learning Best Practices to Design Immunization Training for Health Care Workers in Ghana
}

\author{
Denise Traicoff, ${ }^{a}$ Dieula Delissaint Tchoualeu, ${ }^{a}$ Joseph Opare, ${ }^{b}$ Melissa Wardle, ${ }^{a}$ Pamela Quaye, ${ }^{c}$ \\ Hardeep S. Sandhu, ${ }^{a}$ George Bonsu ${ }^{c}$
}

\section{Key Findings}

- The published literature regarding adult learning and training of trainers provides practical guidance for developing performance-based training of trainers, such as for the Ghana Health Service immunization workforce.

- Training of trainers (TOT), while a common capacitybuilding strategy, presents several risks that must be carefully mitigated.

- The Ghana 2YL TOT was designed with a systems approach, including audience selection, class activities, evaluation methods, and postworkshop action planning.

- Performance-focused class activities, including practice teaching, increased participants' confidence as technicians and trainers.

\section{Key Implications}

- Program managers should consider the risks involved in TOTs and be prepared to support the cascade with human and financial resources.

- Technical experts can take practical steps to ensure TOTs follow adult learning and TOT best practices.

- TOT designers should include opportunities for practice teaching and feedback to prepare participants for their training role.

- Program managers and designers should develop reporting tools and processes and monitor trainers' field activities.

\footnotetext{
a Centers for Disease Control and Prevention Global Immunization Division, Atlanta, GA, USA.

${ }^{\mathrm{b}}$ African Field Epidemiology Network, Accra, Ghana.

${ }^{\mathrm{C}}$ Ghana Health Service, Accra, Ghana.

Correspondence to Denise Traicoff (traicoff.denise@gmail.com).
}

\section{ABSTRACT}

Introduction: A 2016 assessment of frontline health care workers (HCWs) in Ghana identified knowledge, skill, and attitude gaps related to immunization during the second year of life (2YL). The U.S. Centers for Disease Control and Prevention subsequently supported the Ghana Health Service Immunization Program to apply best practices of adult learning and training of trainers (TOT) for a cascade training program for $2 \mathrm{YL}$.

Methods: Five districts from each of the 3 regions (Greater Accra, Northern, and Volta) were selected for the TOT based on key measles and rubella vaccination coverage indicators. The design incorporated best practices of adult learning and TOT. The curriculum integrated 3 major topical themes: technical (immunization topics), operational, and training adults. The technical and operational content was based on HCW tasks most directly affecting $2 \mathrm{YL}$ objectives. A cross-functional team developed all classroom, field activity, and training evaluation materials.

Results: Seventy-four participants attended TOT workshops in 2017. Based on a rubric defined by the course designers, $99 \%$ of the participants reported an acceptable level of confidence to apply and teach the course content. After the TOTs, participants conducted 65 workshops, 43 field visits, and 4 review meetings, reaching 1,378 HCWs within 7 months. Fifty-four percent of HCWs who received training from TOT participants reported an acceptable level of confidence in using the skills, and $92 \%$ reported they would prioritize applying the skills acquired during the training.

Discussion: The success factors for effective adult learning and TOT can be applied to design and implement high-quality TOT even in resource-limited settings. The factors include using a variety of approaches, spending enough class time to prepare TOT participants for their training role, setting specific expectations for cascading the training, and following up through mentorship and reporting. Strong collaboration across the administrative levels of the Ghana Health Service enabled cascade training.

\section{INTRODUCTION}

Cince 2006, the Ghana Health Service Expanded Programme on Immunization (GEPI) has sustained coverage levels of at least $85 \%$ with the first dose of the measles-containing vaccine (MCV1). ${ }^{1}$ In 2012, Ghana introduced the second dose of MCV (MCV2), yet coverage remained well below the intended target, reaching only $63 \%$ in $2015 .^{2}$ This level is well below the recommended $95 \%$ target needed to stop transmission of measles. Additionally, there were gaps in immunization 


\section{The training of trainers model faces several challenges that dilute its effectiveness.}

A baseline
assessment
identified
knowledge, skill,
and attitude gaps
among HCWs in
crucial aspects of
immunization
service delivery
for children in
their second year
of life.

of life. coverage among districts for other vaccines, with 1 in 5 districts not achieving the goal of $>80 \%$ coverage with pentavalent vaccine in $2015 .^{2}$

To strengthen country capacity to prevent, detect, and respond to vaccine-preventable disease threats, GEPI, in collaboration with the United States Centers for Disease Control and Prevention (CDC), led an initiative to strengthen the demand and delivery of vaccines, organized under the term "second year of life" (2YL). Three of the 10 administrative regions, Greater Accra, Northern, and Volta, were selected for the interventions because they contained the greatest number of districts with low MCV2 coverage and inequitable access to immunization services. ${ }^{3}$

To understand the underlying causes of performance gaps contributing to low MCV2 coverage, GEPI and CDC surveyed the knowledge, beliefs, and practices of caregivers and health care workers (HCWs) in 2016, and reviewed the availability of resources at the health facility level that support the 18-month routine immunization visit. ${ }^{3}$ This baseline assessment identified knowledge, skill, and attitude gaps among HCWs in crucial aspects of immunization service delivery for children in their $2 \mathrm{YL}$, particularly concerning national immunization policies, data recording and reporting, tracking children who did not return for additional vaccinations they were due to receive (known as defaulter tracking), and communicating with caregivers. These findings informed the design, implementation, and evaluation of an array of interventions that $\mathrm{CDC}$ supported, such as organizing data improvement teams, conducting social mobilization campaigns, and training staff at the district and health facility level. One training intervention was a 2.5 -day pilot workshop for community health nurses and their supervisors in Greater Accra. After positive results from the pilot, GEPI requested CDC assistance in scaling up the training using a training of trainers (TOT) approach.

Also known as cascade training, TOT is an internationally recognized method for training a large cohort of learners who are usually dispersed geographically. ${ }^{4}$ TOTs rely on a small group of qualified ("master") trainers who train a larger group of individuals, who then in turn train others. This process continues until the entire learner population has been reached. TOTs have been shown to be effective in health settings. ${ }^{5}$ In low-resource countries, TOTs are generally conducted entirely through traditional face-toface classroom instruction, as technology constraints limit distance-based modalities. Although a popular method in both the private sector and public institutions, the TOT model faces several challenges that dilute its effectiveness. For example, studies have indicated several drawbacks to using experts as trainers. Frequently, these individuals are selected based on their technical expertise, a characteristic that does not necessarily translate into an ability to transfer knowledge to novices. ${ }^{6,7}$

Hahn et al. ${ }^{8}$ and Orfaly et al. ${ }^{9}$ point out additional concerns including fidelity to the content, both in terms of accuracy and in adjusting the emphases of content based on the specific target audience. They also describe a more common challenge centered on follow-through, which is the number of trainers who go on to conduct trainings of their own. Pearce et al. ${ }^{5}$ cite turnover of trainers and trainees as threats to long-term impact. In addition, like other workplace learning interventions, factors such as motivation, supervisor support, and triggered action planning can affect whether the trainers apply their new skills. ${ }^{10}$ Finally, it is often challenging to design and implement a valid evaluation method. A key question is whether TOT success should be measured based on the number of trainers trained, the trainers' self-assessment of confidence as a trainer, or the improved proficiency or behaviors by the learners at the lowest level of the training chain. Still, as Hayes ${ }^{11}$ points out, it may not be the TOT model itself that is the problem, but the way it is implemented. Hayes ${ }^{11}$ has proposed 5 critical success factors for TOT in the educational setting that hold promise as a best practice in the public health environment:

1. The method of conducting the training must be experiential and reflective rather than transmissive (i.e., one-directional, such as lectures).

2. The training content and delivery method must be open to reinterpretation rather than prescribe a rigid adherence to a predefined method (i.e., should be sensitive to the local context, while maintaining fidelity to the intent of the content).

3. Expertise must be diffused through the system as widely as possible.

4. Decentralization of responsibilities within the cascade structure is desirable.

5. A cross-section of stakeholders must be involved in the preparation of training materials.

These practices harmonize and overlap with the body of knowledge related to adult learning, as described by andragogy scholars such as Knowles et 
TABLE 1. Ghana Training of Trainer Workshop Topics To Improve Competency in Primary Second Year of Life Vaccination Services

\begin{tabular}{lll}
\hline Technical Topics & \multicolumn{1}{c}{ Operational Topics } & \multicolumn{1}{c}{ Adult Learning } \\
\hline Regional EPI performance & Problem analysis and prioritization & Characteristics of adult learners \\
EPI policies & Process analysis and improvement & Five moments of learning need \\
$2 Y L$ project & Best practices of supportive supervision & Classroom delivery techniques \\
Measles immunogenicity & & Managing the classroom \\
Monitoring data for action & & Choosing the best learning strategy: classroom, small \\
Monthly reporting & groups, one-on-one \\
Data analysis & Developing training action plans \\
Defaulter tracking & & \\
Communicating with caregivers & & \\
\hline
\end{tabular}

Abbreviations: 2YL, second year of life; EPI, Expanded Programme on Immunization; TOT, training of trainers.

al. ${ }^{12}$ and Dirksen. ${ }^{13}$ Specifically, Knowles et al. ${ }^{12}$ proposed 4 principles to apply to adult learning:

1. Adults want to know why they need to learn something.

2. Adults need to learn experientially, based on tasks not theories.

3. Adults approach learning as problem solving or to accomplish a specific goal.

4. Adults learn best when the topic is of immediate value.

This article describes our experience incorporating adult learning best practices and the recommendations of Hayes ${ }^{11}$ into the design and delivery of the TOT intervention for Ghana 2YL and proposes their application in public health workforce development.

\section{METHODS}

The 2 objectives of the TOT were to improve the competency of district health management teams (DHMTs) regarding primary 2YL vaccination services and to improve their capacity as trainers. The training interventions were implemented in all $32 \mathrm{YL}$ regions: Greater Accra, Northern, and Volta. ${ }^{3}$ The target audience included staff at the regional and district levels who were already responsible for providing supportive supervision at the immediate lower level. Five districts from each region were purposively selected to include 2 high-performing districts and 3 low-performing districts based on their MCV2 vaccine coverage, drop-out rates between MCV1 and MCV2, and other Expanded Programme on Immunization (EPI) performance indicators. In each selected district, participants included the regional health management team (RHMT) and approximately 4 DHMT members. Participants worked as a group with their district throughout the workshop.

\section{TOT Curriculum Design}

To achieve the workshop objectives, the curriculum was designed to integrate 3 major themes: technical, operational, and training adults. Training materials were developed by a cross-functional team composed of GHS and CDC staff with expertise in national immunization policy, immunization practices, and adult learning. The technical and operational content was based on the knowledge, skill, and attitude gaps identified by the baseline assessment and is summarized in Table 1.

The 5-day workshop included 2.5 days of technical content, such as GEPI 2YL policy and data analysis, and operational content, such as problem analysis and interpersonal skills. The remaining workshop time was dedicated to strengthening participants' ability and confidence to plan and deliver training to HCWs in their districts. After each workshop, the team made changes to the materials, schedule, or tools to improve and localize subsequent workshops.

\section{Application of TOT Best Practices}

The curriculum design was guided by a fundamental principle for adult learning: workplace training should be learner focused and performance based. ${ }^{14}$ Thus, all technical and operational content was developed and organized based on specific immunization tasks, using participants' own data as much as possible. Hayes' 5 success factors ${ }^{11}$ were integrated into the design and used as a quality check.

\section{Experiential and Reflective Learning}

Adhering to both andragogy principles of Knowles et al. ${ }^{12}$ and recommendations of Hayes ${ }^{11}$, the sessions were highly interactive and used the participants' local context and local immunization data. The workshop introduced practical aspects of

\section{The TOT was intended to improve competency of DHMTs regarding primary 2 YL vaccination services and to improve their capacity as trainers.}

\section{The curriculum design was guided by a fundamental principle for adult learning: workplace training should be learner focused and performance based.}


adult learning to help the trainers plan and deliver the 2YL training themselves. Participants were introduced to the 5 moments of learning need, an adult learning model that helps trainers determine what types of content should be taught in a formal setting and what types of content can be learned informally using job aids or coaching. ${ }^{15}$ This model also reinforces the importance of on-the-job coaching as a factor to encourage learning application. A master trainer conducted review sessions at the end of each day, to review not only the technical content but also the teaching methods. For example, the master trainer led discussions to help participants determine the best training delivery method: workshop, coaching during a health facility visit, or small group review meetings. These daily sessions enabled participants to reflect on what they learned and how they would diffuse the information.

\section{Open to Reinterpretation}

The organizers wanted to balance flexibility while promoting content fidelity. Therefore, the training materials for each topic included formal presentations with speaker notes, exercises with answer keys, and a facilitator's guide. In-class discussions and activities helped participants consider how to localize the content. A detailed lesson plan for the TOT component of the workshop, as well as examples of participant materials, is available in a Supplement.

Teachback was a key activity to support these principles. Participants formed teams of 2 and chose a 20-minute lesson from the 2YL curriculum. They were given electronic versions of all training materials to prepare for their teachback lesson. They were encouraged to customize their lesson while adhering to the lesson's learning objective(s). The master trainers completed a feedback worksheet as they observed the lessons. The participants also received written feedback from their peers immediately after they taught their lesson. Finally, participants applied what they had learned and their knowledge of their district to develop a preliminary training plan, mapping out the number, location, and timeframe of site visits and workshops they expected to deliver.

\section{Diffusion of Expertise and Decentralization of Responsibilities}

Addressing 2 of Hayes' 5 factors, ${ }^{11}$ the design also included components to support the participants after the training as they implemented their plans in the 3 regions. In addition to obtaining electronic versions of all materials, they were mentored by national and regional staff. The participants were encouraged to assess knowledge and skill gaps of the HCWs in their jurisdiction. Their assessment results could help the participants deliver the appropriate content and delivery method and monitor results. Application of operational topics could come in the form of teaching others or applying what they learned to the way they do their work, such as using the lesson Best practices of supportive supervision to improve one's own supervision practices. GEPI instituted a requirement for DHMTs to submit field activity reports specific to this initiative to the higher levels.

\section{Cross-Section of Stakeholders}

The cross-functional team that developed the content also served as master trainers and modeled adult learning best practices when leading the classroom sessions. In addition, RHMTs facilitated the classroom activities to provide local context and joined the national-level staff as mentors for the post-classroom field activities. Table 2 summarizes the program design as it relates to the key practices of effective adult learning and to Hayes ${ }^{\prime 1}$ recommendations.

\section{Monitoring and Evaluation Methods}

Seven methods were used to monitor and evaluate the intervention, either during the workshop, at the end of the workshop, or after the workshop. The evaluation methods were intended to capture if and how the TOT affected the participants, as well as if and how the trainers applied what they learned. Funding was provided to allow master trainers to conduct mentoring visits. In addition, the project budgeted for an impact evaluation that would be conducted after the end of the entire 2YL initiative. Data were collected at $3 \mathrm{key}$ points: at the end of the TOT workshop, via field activity reports submitted by the trainers for the duration of their training activities, and via surveys of the HCWs after they were trained by DHMTs. Table 3 summarizes the intervention's monitoring and evaluation methods and the objective(s) that each addressed. A more detailed description follows.

\section{During the Workshop}

Technical exercises and the teachback were used to evaluate participants' learning. A daily "temperature check" at day's end consisted of plenary discussions to get real-time feedback about how each day went and obtain suggestions for the 
TABLE 2. Summary of Adoption of Adult Learning and Training of Trainers Best Practices

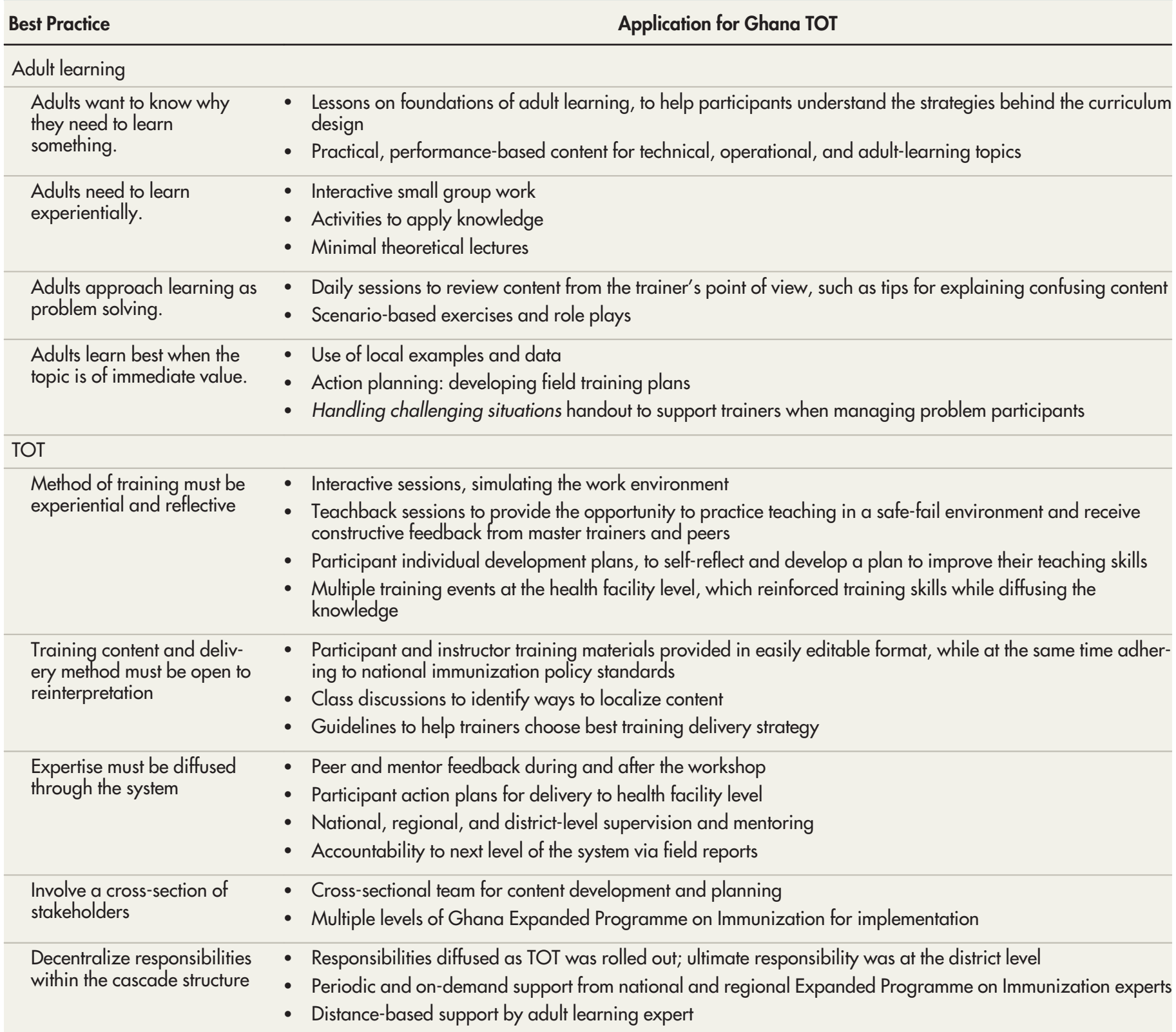

Abbreviation: TOT, training of trainers.

subsequent day. The master trainers conducted daily debriefings to incorporate the suggestions.

\section{End of Workshop}

The purpose of the end of workshop evaluations was to capture lesson usefulness and workshop quality. We used Thalheimer's ${ }^{16}$ method of performance-focused surveys to evaluate workshop quality because it aims to avoid positive bias and measurements that are statistically invalid. This method has participants respond to a series of statements and interprets the quality of training based on a rubric developed by the design team that ranks the acceptability of each statement. Table 4 provides a sample question using the 
TABLE 3. Summary of Ghana Second Year of Life Immunization Training of Trainers Monitoring and Evaluation Methods

\begin{tabular}{|c|c|c|c|}
\hline Intervention Phase & Method & Description & Training Objective \\
\hline \multirow[t]{2}{*}{ During the workshop } & Technical exercises & $\begin{array}{l}\text { Exercises using local data to practice new skills and evaluate } \\
\text { learning. Facilitators and peers provided feedback. }\end{array}$ & $\begin{array}{l}2 Y L \text { vaccination ser- } \\
\text { vices competency }\end{array}$ \\
\hline & Teachback feedback & $\begin{array}{l}\text { To evaluate learning and give trainers constructive feedback } \\
\text { about their training delivery skills }\end{array}$ & Capacity as a trainer \\
\hline $\begin{array}{l}\text { After workshop, field } \\
\text { activities }\end{array}$ & Activity reporting tool & $\begin{array}{l}\text { Electronic survey measuring frequency and process indicators } \\
\text { (where, what, who, when) by recording activities that happened } \\
\text { at the subdistrict level }\end{array}$ & Capacity as a trainer \\
\hline
\end{tabular}

Abbreviations: 2YL, second year of life; DHMT, district health management team; TOT, training of trainer.

TABLE 4. Sample Question From the Training of Trainers Immunization Workshop Evaluation in Ghana

In regard to the technical topics taught, select the SINGLE answer that

best describes what the workshop enabled you to do, if anything.

Ranking Standard

It DID NOT enable me to UNDERSTAND NEW CONCEPTS or USE NEW

SKILLS.

It enabled me to UNDERSTAND SOME NEW CONCEPTS but did NOT

PREPARE ME TO USE NEW SKILLS on the job.

It enabled me to BEGIN TRYING NEW SKILLS on the job.

Unacceptable

It enabled me to CONFIDENTLY USE NEW SKILLS on the job.

It enabled me to BE THOROUGHLY CONFIDENT AND PRACTICED IN

USING NEW SKILLS on the job.

Thalheimer method and includes the acceptability rubric that the team defined. Among other reactions, the survey reported participants' confidence after the workshop from 2 perspectives: their ability to apply what they learned in their workplace and their ability to teach others.

\section{After the Workshop: Field Reporting}

After each 2YL training activity, DHMTs used Open Data Kit $(O D K)^{17}$ (https://getodk.org) software on tablets to report quantitative and qualitative data such as type of training (e.g., workshops, on-thejob training) and when and where trainings occurred. Content was uploaded to a secure cloud server using a mobile data collection platform. They also included their $2 \mathrm{YL}$ training activities in the field reports that they were already providing regularly. These written reports enabled the trainers to reflect on their experiences while providing accountability to the higher levels.

\section{After the Workshop: Evaluation of Impact as a Trainer}

Impact for a TOT is defined as the ability of the new trainers to effectively deliver knowledge and skills. 
Pre- and post-competency assessments were conducted at the health facility level among a systematic random sample of HCWs. As part of the post-assessments, HCWs responded to 7 statements about the quality of the training they received. To define "quality training," the HCWs were asked questions related to trainers' subject matter expertise and trustworthiness, the 2 factors that define a "good" trainer. ${ }^{16}$ We present the HCW assessment on the quality of the training, while data on change in HCW competencies are presented by Tchoualeu et al. ${ }^{18}$

\section{RESULTS}

\section{TOT Participant Characteristics}

From July to September 2017, 3 TOT workshops were held: Greater Accra (24 participants), Northern Region (28 participants), and Volta Region (22 participants). Participants included 4 or 5 health managers from each DHMT, the RHMT, and 2 DHMT members from the next planned TOT location (e.g., 2 district managers from Volta attended the Accra workshop and thus took an active role in the subsequent Volta workshop).

\section{During the Workshop}

Participants worked as district teams throughout the workshop, with multiple opportunities for small-group work as well as plenary discussions. Pairs of participants selected their teachback topic and were coached by the master trainers as they prepared their lessons. In addition to suggestions documented on the teachback feedback sheets, teachback debriefs enabled participants to discuss the training techniques they observed from their peers and share how they would apply them in their own trainings. Participants reported appreciating obtaining specific suggestions from the master trainers as well as from their peers.

\section{End of Workshop}

Of the 74 workshop participants, 68 (92\%) completed the workshop evaluation survey, responding to 4 questions. Table 5 summarizes the survey responses and shows that participants' confidence ranged from "able to begin" applying what they learned to "fully confident" in applying both the technical and the training content. Of these $68,67(99 \%)$ reported a level of confidence that was deemed acceptable or better by the rubric. Fifty-six of 68 responses $(82 \%)$ related to learning engagement fell into the acceptable range. For the question related to opportunities for practice, participants were invited to agree with multiple statements, $80 \%$ of which fell into the acceptable range. Ten responses were unacceptable, and the statement, "I was given too much practice," defined in the rubric as a red flag, meaning it would require further investigation, received 11 (16\%) responses. For the unacceptable and red flag responses, further investigation was done by inspecting the comments sections of the surveys and by interviewing the workshop facilitators. Based on the feedback, the team improved the materials and/or the workshop schedule.

\section{After the Workshop: Field Activities}

Using the reporting tool, field activities were reported between November 2017 and June 2018. All 5 districts in Greater Accra and 3 of 5 districts each in Northern and Volta Regions submitted reports, reporting a total of 112 activities across the 3 regions. ${ }^{18}$ Most reported that they had conducted workshops $(n=65)$, followed by health facility visits $(n=43)$. Very few reported that they had conducted review meetings $(n=4)$. The TOT participants reported training a total of 1,378 HCWs (Greater Accra $=440$, Volta= 405, Northern=533). Northern Region submitted the greatest number of activity reports $(n=60)$, followed by Volta Region $(n=30)$ and Greater Accra $(n=22)$. DHMTs also reported the topics they taught. The Figure provides a summary of all training activities by region.

\section{After the Workshop: Evaluation of Impact as a Trainer}

In addition to being assessed for knowledge, skill, and attitude, 575 HCWs were surveyed about the training usefulness and facilitator presentation skills: 90 in Greater Accra (Adenta district), 54 in Northern (Tamale Metro), and 431 in Volta (all 5 districts). ${ }^{17}$ Related to increased aptitude, $54 \%$ of all respondents reported confidence in using the new skills, with $45 \%$ reporting the ability to begin to try the new skills. Moreover, $92 \%$ of all respondents reported that they would make it a high priority to use their new skills, and $81 \%$ reported that the concepts will "help me significantly to improve my work outcomes." As defined by the analysis rubric agreed upon by the stakeholders, only 1 question received any unacceptable response: $2 \%$ of respondents reported that the content would "Will help me slightly to improve my work outcomes." Regarding their experience with the instructors, a question that 
TABLE 5. Summary of Ghana Expanded Programme on Immunization Training of Trainers Workshop Evaluation ( $n=68)$

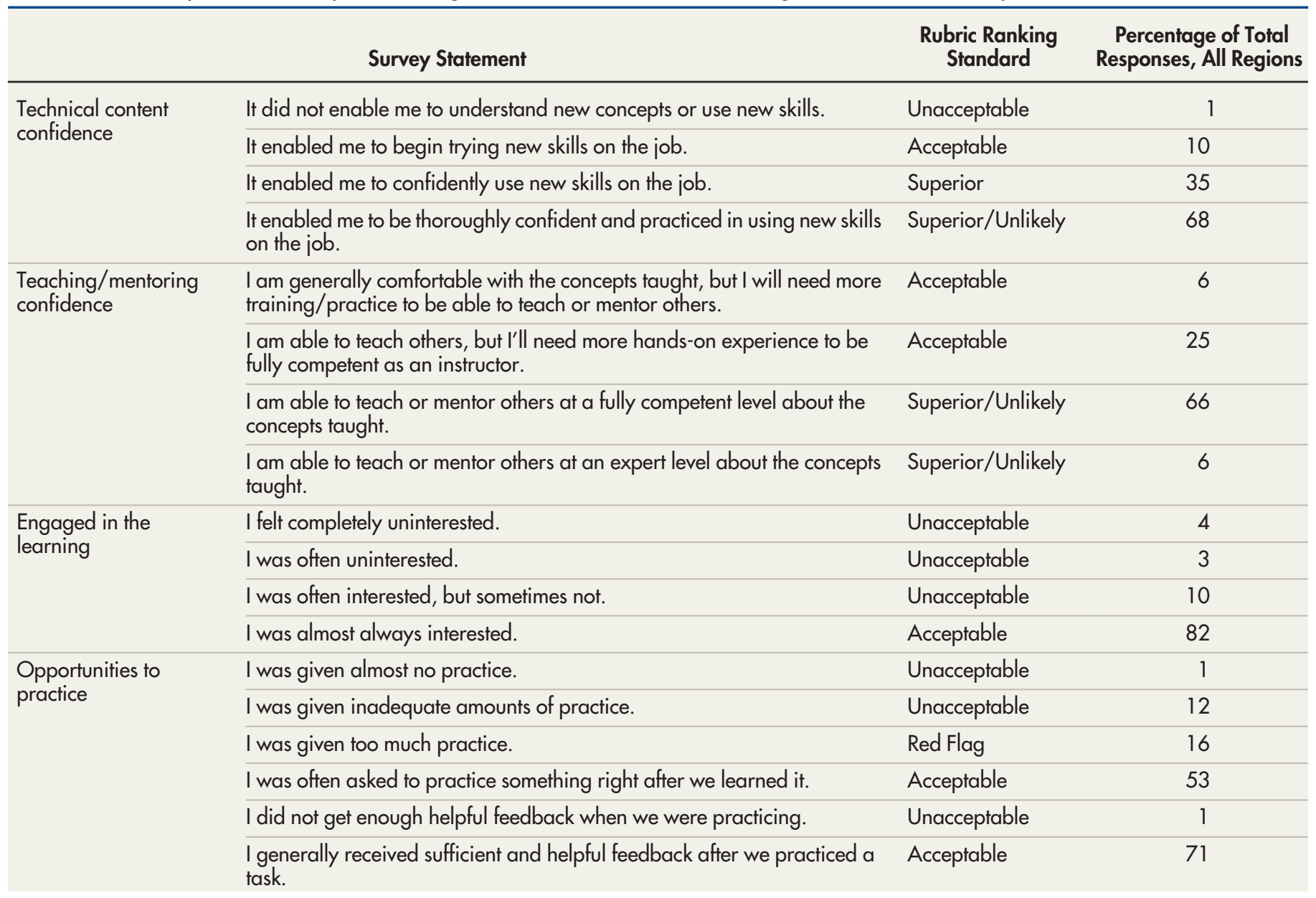

allowed for multiple responses, all responses fell within the rubric's definition of acceptable. Of the 575 responses, 300 (52\%) reported the instructor "demonstrated a high level of realworld experience," $162(28 \%)$ reported the instructor "showed deep subject matter expertise," $377(66 \%)$ reported "I was often asked to practice something right after we learned it," and $237(41 \%)$ reported, "I generally received sufficient and helpful feedback after we practiced a

\section{task." No unacceptable responses (e.g. "'I was given inadequate amounts of practice") were reported. \\ health facility \\ survey results}

enabled us to

design the TOT

intervention

based on real-

world

representative

data. such as communicating with caregivers. Integrating operational skill building in the context of completing technical tasks, rather than developing a separate "management" curriculum, recognized that staff could require both types of skills to complete a single task, such as improving defaulter tracking. Devoting half of the class time to practical components of adult learning theory, enabling them to practice-teach in a supportive environment, and setting clear expectations of the new trainers helped prepare the participants in a very practical way. Hayes' success factors ${ }^{11}$ were a useful check during the training development process.

Most TOT participants reported increased confidence in applying and teaching the technical content, yet this finding is tempered by studies that have shown workers regularly overestimate their ability. ${ }^{19}$ This phenomenon could explain the notable percentage of responses that our rubric deemed superior/unlikely. Because of the 
FIGURE. Summary of 112 Reported Training Activities in Greater Accra, Northern, and Volta Regions by Region and Method, in Ghana 2017

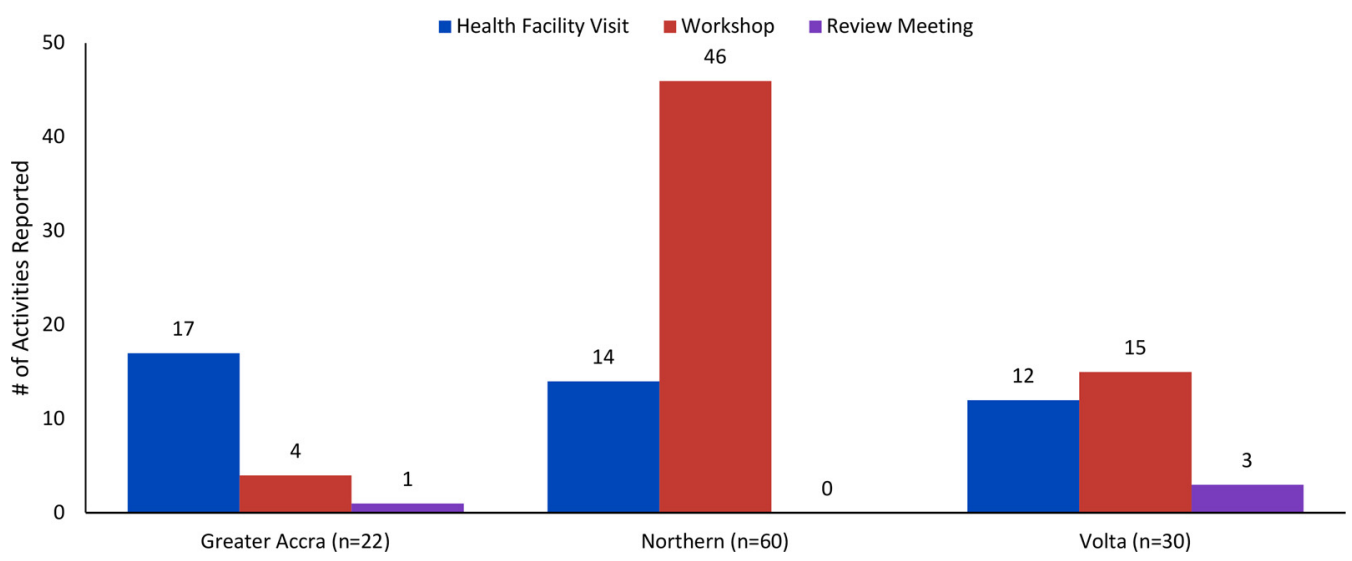

complex nature of the content and our inclusion of mentorship as a component of the intervention, the TOT rubric defined as acceptable if the participants felt less than fully confident at the end of the workshop. Regarding learning engagement, it is important to note that while most participants' responses were categorized as acceptable by our rubric, the small proportion who reported that they were "often interested but sometimes not" were deemed unacceptable. It may be reasonable to expect adult learners to experience occasional disengagement, and thus care should be taken by training designers when defining their rubrics. We leave it to the reader to determine if it is reasonable to expect that learners will occasionally "tune out." Finally, we were concerned with the number of unacceptable and red flag responses related to opportunities to practice. These responses were discussed with regional and national leaders in Ghana. The leaders were pleased with the interactivity and requested no major changes to the workshop design.

Regarding the evaluation methods, we found Thalheimer's ${ }^{10}$ performance-focused survey method more actionable than traditional Likert scale workshop satisfaction surveys, as it not only reduces ambiguity for the participant, but it forces the training designer and stakeholders to think more specifically about the performance improvement they expect from the training. The "most useful lesson" group activity was helpful: in addition to providing the master trainers with timely and detailed feedback, the activity provided an interactive means for participants to review the workshop lessons and envision themselves applying what they learned.
Regarding the field activities, although the trainers chose workshops as their primary training method, it was encouraging to see that it was possible for them to teach the 2YL content using small-group meetings at the health facility or one-on-one coaching, both of which occur on the job with minimal disruption to the workflow. The master trainers who observed the DHMT-led workshops noticed a high degree of comfort with the technical content as well as the application of the adult learning principles that were stressed in the workshops. Through the field activity reports, we were able to partially track the follow-through that Hahn et al. ${ }^{8}$ and Orfaly et al. ${ }^{9}$ recommended.

Based on the participants' self-reported technical and training confidence, their action plans, and their field reports, the stakeholders considered the TOT a success. The cross-functional team, composed of technical EPI and workforce development experts, supported an intervention that was technically accurate and practical to deploy in Ghana's setting. Yet none of these factors were as influential as the posttraining actions in the 3 regions: the regional and district teams were open to taking the time to learn new ways of doing their own work and training others in a purposeful way.

We appreciate that all these practices may not be possible in low-resource settings. Still, Pearce et al. ${ }^{5}$ suggested that a combination of teaching techniques can help to effectively disseminate content to health workers. We propose, then, that the following combination of factors can support an effective TOT:

\section{Based on the participants' self- reported technical and training confidence, their action plans, and their field reports, the TOT was considered a success.}


- Use learning science to inform analysis, design, delivery, and evaluation of the intervention.

- Define specific performance gaps and expected behavior change to inform the content and learning activities.

- Use a variety of components such as those described in Table 2 to build capacity as trainers.

- Spend enough class time to prepare participants for their training role.

- Ensure that the technical content is practical (i.e., activity based) and not just a review of theories or policies.

- Provide instructor materials such as lesson outlines that sketch out how to conduct the lesson.

- Use performance-focused evaluation methods such as Thalheimer's ${ }^{10}$ to add rigor to the workshop evaluations.

- Give the trainers specific tasks and expectations, then monitor their field activities.

- Budget for trainer field support and postintervention evaluation.

- Engage regional and local support for the trainers.

\section{Limitations}

With the availability of technology and acceptance of text messaging platforms in even the most remote areas, we think that we could have integrated technology into the design to a greater extent: peer networks and electronic checklists could provide valuable performance support.

Since field activities were reported at the district level without direct oversight of the project team, we were unable to calculate the number of TOT participants who went on to teach. The lack of resources for a field monitoring team also prevented us from conducting a more rigorous evaluation of the participants' impact as a trainer, and we were only able to rely on the learners' perceptions. Additionally, the complete absence of reporting for 2 of the 5 districts in both Northern and Volta regions demonstrates that we cannot know how many activities did occur that were simply not reported. In future efforts, we will engage the trainers earlier in the project to determine a more realistic means for collecting data. We are concerned about sustainability and are looking forward to learning if and how TOT practices continue if external funding and technical support are absent. We also await the findings of the end-of-project evaluation to see if and how performance at the health facility level has improved.

\section{CONCLUSIONS}

Our experience demonstrates how the best practices of adult learning and TOT can support performance-focused training that is applied on the job, although the specifics of the Ghana 2YL initiative should be adapted for local circumstances. We hope the description of methods and tools is specific enough that readers can adapt them for their context. We also believe our findings reinforce the importance of conducting a performance-based baseline assessment and for budgeting resources to enable rigorous monitoring and evaluation. Finally, regardless of the circumstances, strong collaboration and a united purpose such as that demonstrated by the Ghanaian EPI staff at the national, regional, district, and health facility levels created an environment that supported the 2YL TOT.

Acknowledgments: Special thanks to GEPI staff Dr. Kwame AmponsaAchiano, John Dadzie, and Fred Osei-Sarpong, who assisted with materials development and as master trainers. Thanks to the GHS regional and district health management teams in Greater Accra, Northern, and Volta regions who participated in the workshops and cascaded their knowledge. We appreciate CDC colleagues who provided technical and logistical assistance, particularly Mawuli Nyaku, Linda Osadebe, and Colleen Scott. We are also grateful to Kathy Banke and Chung-Won Lee for editing and technical advice in the development of this article.

Funding: Global Health Security Agenda funded the Centers for Disease Control and Prevention Immunization Second Year of Life project

Disclaimer: The views are those of the authors and do not reflect the official position of the U.S. Centers for Disease Control and Prevention or the International Vaccine Institute.

Author contributions: D. Traicoff developed course materials, taught adult learning sessions, served as master trainer, facilitated teachback, wrote sections of the manuscript, and managed co-author reviews. D. Tchoualeu developed course materials, taught technical sessions, served as master trainer, wrote sections of the manuscript, and reviewed drafts. J. Opare developed course materials, taught technical sessions, served as master trainer and field advisor, wrote sections of the manuscript, and reviewed drafts. M. Wardle led baseline assessment, developed course materials, taught technical sessions, wrote sections of the manuscript, and reviewed drafts. P. Quaye developed course materials, taught technical sessions, served as master trainer and field advisor, wrote sections of the manuscript, and reviewed drafts. H. Sandhu reviewed and approved project protocols, provided project technical consultation, provided human resources to conduct field work, and reviewed drafts of the manuscript. G. Bonsu defined performance goals, oversaw TOT courses and field activities, provided project technical consultation, provided teachback and fieldwork feedback, provided human resources to conduct field work, and reviewed drafts of the manuscript.

Competing interests: None declared.

\section{REFERENCES}

1. World Health Organization (WHO). WHO vaccine-preventable diseases: monitoring system 2018 global summary. Accessed May 12, 2021. http://apps.who.int/immunization_monitoring/ globalsummary/countries? countrycriteria $\% 5 \mathrm{~B}$ country $\% 5 \mathrm{D} \% 5 \mathrm{~B} \%$ $5 \mathrm{D}=\mathrm{GHA}$ 
2. Ghana Health Service (GHS). Field Guide for the Ghana Immunization Programme. GHS; 2012.

3. Nyaku M, Wardle M, Eng JV, et al. Immunization delivery in the second year of life in Ghana: the need for a multi-faceted approach. Pan Afr Med J. 2017;27(Suppl 3):4. CrossRef. Medline

4. Karalis T. Cascade approach to training: theoretical issues and practical applications in non-formal education. Journal of Education and Social Policy. 2016;3(2):104-108. Accessed April 23, 2021. https://www.researchgate.net/publication/309493304 Cascade_Approach_to_Training_Theoretical_Issues_and_Practical_ Applications_in_Non_-Formal_Education

5. Pearce J, Mann MK, Jones C, van Buschbach S, Olff M, Bisson JI. The most effective way of delivering a train-the-trainers program: a systematic review. J Contin Educ Health Prof. 2012;32(3):215-226. CrossRef. Medline

6. Williams SW. The effectiveness of subject matter experts as technical trainers. Hum Resour Dev Q. 2001;12(1):91-97. CrossRef

7. Hinds PJ, Patterson M, Pfeffer J. Bothered by abstraction: the effect of expertise on knowledge transfer and subsequent novice performance. J Appl Psychol. 2001;86(6):1232-1243. CrossRef. Medline

8. Hahn EJ, Noland MP, Rayens MK, Christie DM. Efficacy of training and fidelity of implementation of the life skills training program. J Sch Health. 2002;72(7):282-287. CrossRef. Medline

9. Orfaly RA, Frances JC, Campbell P, Whittemore B, Joly B, Koh H. Train-the-trainer as an educational model in public health preparedness. J Public Health Manag Pract. 2005;1 1 (Supplement):S123S127. CrossRef. Medline

10. Thalheimer $W$. Factors that support training transfer: a brief synopsis of the transfer research. Work-Learning Research Inc; 2020.
Accessed May 12, 2021. https://www.worklearning.com/wpcontent/uploads/2020/01/Transfer-of-Training-Quick-ResearchReview-2020-vla.pdf

11. Hayes D. Cascade training and teachers' professional development. ELTJ. 2000;54(2):135-1 45. CrossRef

12. Knowles MS, Holton EF, Swanson RA. The Adult Learner. 7th ed. Routledge Taylor \& Francis Group; 2012.

13. Dirksen J. Design for How People Learn. 2nd ed. New Riders; 2015.

14. Stolovitch H, Keeps E. Telling Ain't Training. American Society for Training and Development; 2002.

15. Gotffredsen C, Mosher B. Are you meeting all five moments of learning need? Learning Solutions. Accessed May 12, 2021. https:// www.learningsolutionsmag.com/articles/949/are-you-meetingall-five-moments-of-learning-need

16. Thalheimer W. Performance-Focused Smile Sheets: A Radical Rethinking of a Dangerous Art Form. Work-Learning Press; 2016.

17. Hartung C, Lerer A, Anokwa Y, et al. Open Data Kit: tools to build information services for developing regions. Paper presented at: ICTD '10: Proceedings of the 4th ACM/IEEE International Conference on Information and Communication Technologies and Development, December 2010; 18:1-12. CrossRef

18. Tchoualeu D, Harvey B, Nyaku M, et al. Evaluation of the impact of immunization second year of life training interventions on health care workers in Ghana. Glob Health Sci Pract. 2021 ; 9(2). CrossRef

19. Kruger J, Dunning D. Unskilled and unaware of it: how difficulties in recognizing one's own incompetence lead to inflated self-assessments. J Pers Soc Psychol. 1999;77(6):1121-1 134. CrossRef. Medline

\section{Peer Reviewed}

Received: January 7, 2021; Accepted: May 4, 2021

Cite this article as: Traicoff D, Tchoualeu DD, Opare J, et al. Applying adult learning best practices to design immunization training for health care workers in Ghana. Glob Health Sci Pract. 2021;9(3):487-497. https://doi.org/10.9745/GHSP-D-21-00090

(C) Traicoff et al. This is an open-access article distributed under the terms of the Creative Commons Attribution 4.0 International License (CC BY 4.0), which permits unrestricted use, distribution, and reproduction in any medium, provided the original author and source are properly cited. To view a copy of the license, visit https://creativecommons.org/licenses/by/4.0/. When linking to this article, please use the following permanent link: https:// doi.org/10.9745/GHSP-D-21-00090 